metropolitan hospital medical school cannot give an equally good education for a smaller sum, which is very possible, its authorities should either raise their fees or adopt some form of combination with other schools to get rid of the suicidal wastefulness which is involved in each hospital keeping up a school for the teaching of subjects which have nothing to do with the hospitals at all.

$\mathrm{WT}_{\mathrm{A}}$ have very little doubt that it is under the glamour of the idea that a great school is absolutely essential to a great hospital, that students must be attracted, that a talented staff must be drawn together by the offer of teaching facilities, and that the money given to the school is but a payment for advantages obtained by the patients in virtue of the connection of the hospital with the school-advantages which could not otherwise be obtained-that the managers of certain hospitals have occasionally been led to subsidise their schools.

We think, however, that this is an entirely false view of the situation. As a matter of fact, the student is by no means essential to the hospital, however advantageous his presence may be. This is proved by the knowledge that there are many large hospitals of undoubted efficiency where there are no students at all. But the hospital is absolutely essential to the student. By no stretch of imagination can we conceive of a student obtaining an efficient medical education without a hospital. How then, it may fairly be asked, has such a hospital as the London $\epsilon$ ver been led to grant a couple of thousand a-year to its medical school, and thus make a present of, say, $£ 20$ worth of education free gratis and for nothing to every student who enters there?

The answer is that the whole thing has arisen from the undue multiplication of schools in the metropolis, from their unreasonable competition with each other, and from the lamentable absence of business capacity and power of combination, which has allowed each school to endeavour to be complete in itself, and to maintain that it is equal to its neighbours in every branch of knowledge.

The remedy, then, is to be sought in a federation of several metropolitan medical schools for the purpose of providing the student with the best instruction in the subjects. which occupy the first two years of his medical career. This could readily be done on the basis already indicated, and the sooner it is taken in hand the better it will be for the interests of all concerned. As we have shown, this improved system would in no way interfere with the present high standard of medical and surgical work to be found in our great hospitals. There the clinical instruction must always be given, and there practical medicine and surgery must be taught, so that our great school hospitals must continue to attract the most highly qualified medical staff, whose teaching the medical student will gladly avail himself of, $\epsilon$ specially when he is guaranteed-as he would then be guaranteed-that in seeking it he is incurring no risk of being charged with having deprived the poor of money given for their relief and medical treatment.

\title{
CHLOROFORM ADMINISTRATION.
}

Dr. DUDL EY BUxton not unnaturally feels that some apology is needed for addressing the world at large by way of the Nineteenth Century Review, on the subject of deaths under chloroform. Nevertheless, we may quite properly approve of the course he has taken, in that what he has done has given a very effective reply to the nonsense that the same paper had printed in a previous issue in praise of a reputed "safe method" of chloroform administration, a method which has been, perhaps more appropriately, described by a recent scientific observer as "the slap-dash method." Dr. Dudley Buxton gives to the Hyderabad Commission full praise for having demonstrated afresh the dangers to respiration which occur in administering chloroform, dangers which, as he says, have been recognised and carefully taught for over forty years. But he maintains that, when attempts are made to go beyond this, and to assert, as was asserted in a certain daily paper, that the Commission had shown that "to take chloroform was as safe as to take a tumbler of whiskey and water," it becomes the duty of those with technical knowledge to call a halt, and to point out that dangers do exist over and above that of an asphyxia caused by carelessness in administering chloroform. No death from chloro. form due to asphyxia ought to happen, nor will it occur in competent hands in the case of an average patient. But there are other causes of death; and we think that Dr. Dudley Buxton is right in saying that "it is a severe and an unjust charge, unsupported by the weight of scientific evidence, to say that all deaths from chloroform are deaths from asphyxia, and are therefore unnecessary, avoidable, and consequently criminal deaths." We are quite sure that he is right also in saying that "it is distinctly a straining of truth to aver that those who have followed Syme's instructions.... have enjoyed an immunity from danger whilst giving chloroform." There can, we think, be no doubt that this slap. dash method is responsible for many of the deaths from chloroform, and we can hardly express the views which this journal has held on the subject better than in Dr. Dudley Buxton's own words: "All recognise the danger of paralysing the brain centres with chloroform, and so causing asphyxia, and always have recognised it, but the weight of both modern and less recent experiment and clinical observation compe!s us to recognise also the second and far more terrible danger, that of the onset of syncope from the direct action of chloroform upon the heart muscle." 